ARTICLE

\title{
Analyses of Assay Data of LWR Spent Nuclear Fuels with a Continuous-Energy Monte Carlo Code MVP and JENDL-4.0 for Inventory Estimation of ${ }^{79} \mathrm{Se},{ }^{99} \mathrm{Tc},{ }^{126} \mathrm{Sn}$ and ${ }^{135} \mathrm{Cs}$
}

\author{
Keisuke OKUMURA ${ }^{1,{ }^{*}}$, Shiho ASAI ${ }^{1}$, Yukiko HANZAWA ${ }^{1}$, Hideya SUZUKI ${ }^{1}$, \\ Masaaki TOSHIMITSU ${ }^{1}$, Jun INAGAWA ${ }^{1}$, Tsutomu OKAMOTO ${ }^{1}$, Nobuo SHINOHARA ${ }^{1}$, \\ Satoru KANEKO ${ }^{2}$ and Kensuke SUZUKI ${ }^{2}$ \\ ${ }^{1}$ Japan Atomic Energy Agency, 2-4 Shirakata, Tokai-mura, Naka-gun, Ibaraki-ken, 319-1195, Japan \\ ${ }^{2}$ Tokyo Electric Power Company, 1-1-3 Uchisaiwai-cho, Chiyoda-ku, Tokyo, 100-8560, Japan
}

\begin{abstract}
For accurate inventory estimation of long-lived fission products in LWR spent nuclear fuels, a new burn-up chain model was developed, and the latest nuclear data were employed for neutron cross sections, fission yields, half-lives, and so on. Most of them are taken from JENDL-4.0. MVP-BURN with the latest nuclear data was applied to four destructive assay data of spent nuclear fuels including inventory measurements of ${ }^{79} \mathrm{Se},{ }^{99} \mathrm{Tc},{ }^{126} \mathrm{Sn}$ and ${ }^{135} \mathrm{Cs}$. One of them is new measurement data obtained by JAEA. From the analyses of isotopic composition, it is found that the new data by JAEA are consistent with the other assay data obtained by different laboratory with different techniques. It is also confirmed that the present calculation results show good agreements with experimental ones for ${ }^{79} \mathrm{Se}$ and ${ }^{135} \mathrm{Cs}$ within about $10 \%$. In contrast, amounts of ${ }^{99} \mathrm{Tc}$ and ${ }^{126} \mathrm{Sn}$ are overestimated by up to about $50 \%$. These discrepancies are likely due to the effect of insoluble residue produced during sample dissolution and / or errors of fission yields in the analyses.
\end{abstract}

KEYWORDS: Monte Carlo burn-up calculation, assay data of spent nuclear fuel, post irradiation examination analyses, JENDL-4.0, LWR spent nuclear fuel composition, long-lived fission products, ${ }^{79} \mathrm{Se},{ }^{99} \mathrm{Tc},{ }^{126} \mathrm{Sn},{ }^{135} \mathrm{Cs}$

\section{Introduction}

The accurate inventory estimation of long-lived fission products (LLFPs) is important for the quality management of high-level radioactive vitrified wastes and for long-term safety assessment of a geological disposal of the vitrified wastes. With the support of Japanese electric power companies, Japan Atomic Energy Agency (JAEA) started the study to develop an accurate inventory estimation method for LLFPs, such as ${ }^{79} \mathrm{Se},{ }^{99} \mathrm{Tc},{ }^{126} \mathrm{Sn}$, and ${ }^{135} \mathrm{Cs}$ in the high-level radioactive waste (HLW) from Japanese reprocessing plant. ${ }^{1)}$ These nuclides have difficulties in radiochemical analyses compared with other fission products or actinides. Therefore, available assay data of spent nuclear fuels are limited and nuclear data, such as neutron-induced cross sections, fission yields, or decay half-lives are not always known exactly for these LLFPs.

As the first step of the inventory estimation study, a post irradiation examination (PIE) was newly carried out for the well-characterized $\mathrm{UO}_{2}$ fuel irradiated in a Japanese PWR (Ohi-1). In the examination, concentrations of ${ }^{79} \mathrm{Se},{ }^{99} \mathrm{Tc}$, ${ }^{126} \mathrm{Sn}$ and ${ }^{135} \mathrm{Cs}$ were measured for the first time in Japan. ${ }^{2,3)}$

In order to confirm the validity of the measurement data, a PIE analysis was carried out with a burn-up calculation code MVP-BURN ${ }^{4}$ based on the continuous-energy Monte Carlo method and the latest nuclear data from JENDL-4.0 $0^{5}$

*Corresponding author, E-mail: okumura.keisuke@jaea.go.jp

(C) 2011 Atomic Energy Society of Japan, All Rights Reserved. and so on. In addition, PIE analyses were also performed for old but precious data including measurements of ${ }^{79} \mathrm{Se},{ }^{99} \mathrm{Tc}$, ${ }^{126} \mathrm{Sn}$ and ${ }^{135} \mathrm{Cs}$. The old data was obtained by Pacific Northwest Laboratory (PNL) for six, nine and four $\mathrm{UO}_{2}$ fuel samples irradiated in Cooper (BWR), Calvert-Cliffs-1 (PWR) and H. B. Robinson-2 (PWR), respectively. ${ }^{6,7)}$ The experimental data are well summarized in the "Spent Fuel Isotopic Composition Database (SFCOMPO)",8) developed by JAEA and published on the web site of OECD/NEA.

In the present study, we show the results of PIE analyses for LLFPs of Ohi-1, Cooper, Calvert-Cliffs-1 and H. B. Robinson-2 with the up-to-date data and method, and discuss the reliability of the measured and calculated data by comparison of burn-up behaviors of each nuclide.

\section{Data and Method}

MVP-BURN is a burn-up calculation code by combination of a continuous-energy Monte Carlo code MVP ${ }^{9)}$ and an isotope generation and depletion calculation module based on the method of the DCHAIN code. ${ }^{10)}$

Figure 1 shows the burn-up chain model developed for the present study. It can treat many fission products which are important not only for evaluation of neutronic characteristics but also for safety assessment of radioactive wastes.

In addition to the point-wise neutron cross sections, fission yields and isomeric ratios are taken from JENDL-4.0, which was released on May 2010. 


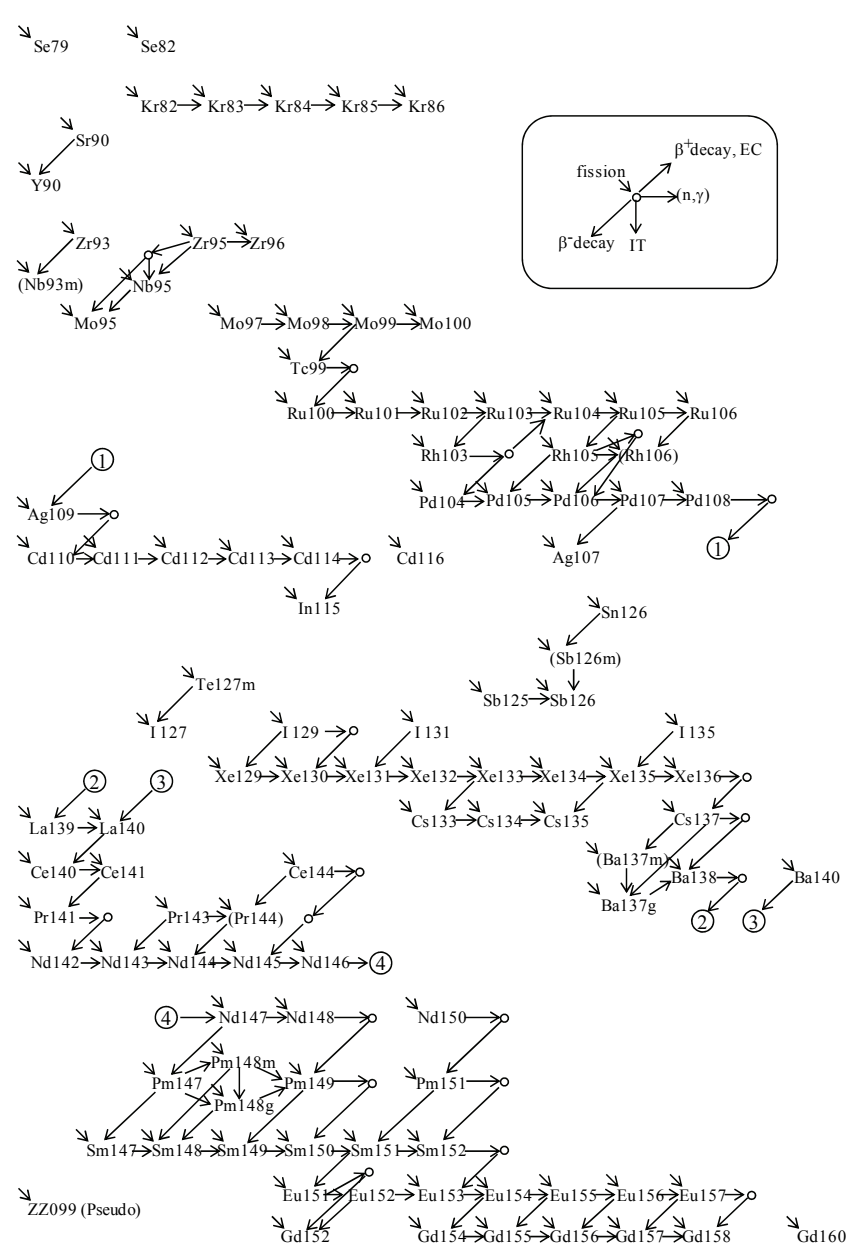

B10

Er162 Er164 Er166 $\rightarrow$ Er167 $\rightarrow \operatorname{Er} 168 \quad \operatorname{Er} 170$

$\mathrm{Hf} 176 \rightarrow \mathrm{Hf} 177 \rightarrow \mathrm{Hf} 178 \rightarrow \mathrm{Hf} 179 \rightarrow \mathrm{Hf} 180 \rightarrow \mathrm{Hf} 181 \rightarrow \mathrm{Hf} 182$

Fig. 1 Burn-up chain model for fission products and burnable poisons

Half-lives of decay nuclides are taken from the recent "Evaluated Nuclear Structure Data File (ENSDF, revised as of Oct. 2008)"11) except for ${ }^{79} \mathrm{Se}$ and ${ }^{126} \mathrm{Sn}$. For these nuclides, the most recent possible half-lives are employed; they are $(3.77 \pm 0.19) \times 10^{5} \mathrm{y}^{12)}$ and $(1.98 \pm 0.06) \times 10^{5} \mathrm{y}^{13)}$ respectively.

As for a geometrical modeling, an infinite lattice of two-dimensional square unit pin cell was employed through the present study. However, the water density was adjusted to reproduce ratio of hydrogen-to-uranium atomic numbers $(\mathrm{H} / \mathrm{U})$ at the axial position of each sample fuel in the fuel assembly.

The new burn-up chain model and nuclear data were first validated by application to the PIE analysis of a sample fuel $\left(\right.$ SF97-4) ${ }^{8,14)}$ discharged from a Japanese PWR (Takahama-3). ${ }^{15)}$ Here, we show, in Fig. 2, a summary of calculated to experimental values $(\mathrm{C} / \mathrm{E})$ for concentrations of major nuclides, because the target LLFPs are not included in this examination. Error bars in the figure are experimental uncertainties $(2 \sigma)$ where error propagation due to cooling time

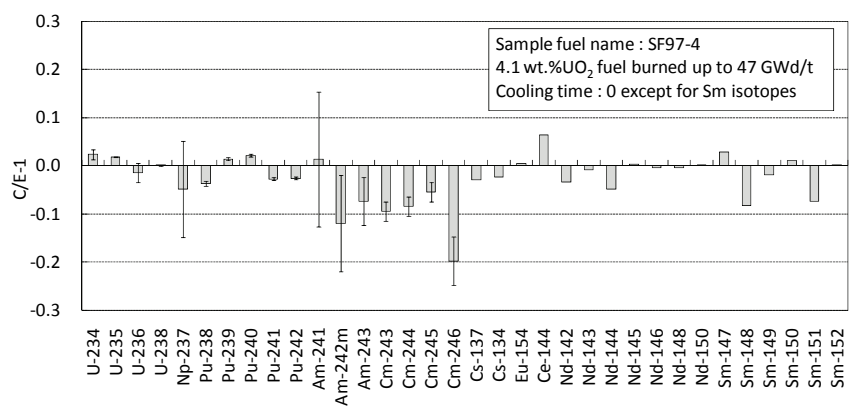

Fig. 2 Result (C/E-1) of Takahama-3 PIE analysis ${ }^{15)}$

correction is considered. We can see that MVP-BURN with the latest nuclear data gives very good agreement for the spent nuclear fuel composition (in unit of $\mathrm{kg} / \mathrm{MTU}^{\mathrm{a}}$ ) of $\mathrm{UO}_{2}$ within about $10 \%$ except for ${ }^{246} \mathrm{Cm}(\sim 20 \%)$.

\section{Assay Data of Spent Nuclear Fuels for Long- Lived Fission Products}

\section{Ohi-1}

The 3.2 wt.\% enriched $\mathrm{UO}_{2}$ fuel was irradiated up to 44.9 $\mathrm{GWd} / \mathrm{t}$ in a $17 \times 17$ type 4 -loop commercial PWR (Ohi-1). Irradiation history of the fuel is reported in Reference 2. A sample fragment of the $\mathrm{UO}_{2}$ fuel was cut out at the distance of $1,790 \mathrm{~mm}$ from the lower distal part of the fuel rod. It was dissolved with $4 \mathrm{M}$ nitric acid in a hot cell. The resultant solution was filtered to remove insoluble residue. After Se, Tc, Sn, and Cs were chemically separated, the concentrations of ${ }^{79} \mathrm{Se},{ }^{99} \mathrm{Tc},{ }^{126} \mathrm{Sn}$ and ${ }^{135} \mathrm{Cs}$ (cooling time: 20.4 year) were determined with an inductively coupled plasma quadrupole mass spectrometer (ICP-QMS). ${ }^{2,3)}$ The ICP-QMS is suitable for the measurement of isotopic composition with enough accuracy compared with our target accuracy (less than 30\%).

\section{Cooper, Calvert Cliffs-1 and H. B. Robinson-2}

As shown in Table 1, radiochemical measurements were made by PNL for six samples from the Cooper reactor $(7 \times 7$

Table 1 Major parameters of sample fuels in PIEs of Cooper, Calvert Criffs-1 and H. B. Robinson-2

\begin{tabular}{|c|c|c|c|c|c|}
\hline $\begin{array}{c}\text { Assembly } \\
\text { ID }\end{array}$ & $\begin{array}{l}\text { Rod } \\
\text { ID }\end{array}$ & $\begin{array}{l}\text { U235 } \\
\text { (wt.\%) }\end{array}$ & $\begin{array}{r}\text { Burn-up } \\
(\mathrm{GWd} / \mathrm{t})\end{array}$ & $\begin{array}{c}\text { Cooling } \\
\text { time (year) }\end{array}$ & $\begin{array}{c}\text { Measured } \\
\text { FPs }\end{array}$ \\
\hline \multicolumn{6}{|c|}{ Samples irradiated in Cooper reactor } \\
\hline CZ346 & ADD2966 & 2.94 & 18.96 & 5.35 & \multirow{6}{*}{$\begin{array}{l}\text { Se-79, } \\
\text { Sr-90, } \\
\text { Tc-99, } \\
\text { Sn-126, } \\
\text { Cs-135, } \\
\text { Cs-137 }\end{array}$} \\
\hline CZ346 & ADD2966 & 2.94 & 33.07 & 5.35 & \\
\hline $\mathrm{CZ346}$ & ADD2966 & 2.94 & & & \\
\hline CZ346 & ADD29 & 2.94 & & 28 & \\
\hline $\mathrm{CZ346}$ & ADD2974 & & & & \\
\hline $\mathrm{CZ346}$ & ADD2974 & 2.94 & 31.04 & 5.28 & \\
\hline \multicolumn{6}{|c|}{ Samples irradiated in Calvert Cliffs -1 reactor } \\
\hline D047 & MKP109 & 3.04 & 27.35 & 5.12 & \multirow{9}{*}{$\begin{array}{l}\mathrm{Se}-79 \\
\mathrm{Sr}-90 \\
\mathrm{Tc}-99 \\
\mathrm{Sn}-126 \\
\mathrm{Cs}-135 \\
\mathrm{Cs}-137\end{array}$} \\
\hline D047 & MKP & 3.04 & & & \\
\hline D047 & MKP109 & 3.04 & & 5.12 & \\
\hline D0101 & MLA098 & 2.72 & 18.68 & 6.5 & \\
\hline D0101 & $\mathrm{ML}$ & 2.72 & 26 & 6.5 & \\
\hline D0101 & MLA0 & 2.72 & 33.17 & 6.5 & \\
\hline BT03 & NBD107 & 2.45 & 1.4 & 6.7 & \\
\hline BT03 & NBD107 & 2.45 & 37.27 & 6.7 & \\
\hline BT03 & NBD107 & 2.45 & 46.46 & 6.7 & \\
\hline \multicolumn{6}{|c|}{ Samples irradiated in H. B. Robinson-2 reactor } \\
\hline BO-5 & N9 & 2.56 & 16.02 & 10.78 & \multirow{4}{*}{$\begin{array}{l}\text { Tc-99, } \\
\text { Cs-137 }\end{array}$} \\
\hline BO-5 & N9 & 2.56 & 23.81 & 10.78 & \\
\hline BO-5 & N9 & 2.56 & 28.47 & 9.94 & \\
\hline $\mathrm{BO}-5$ & N9 & 2.56 & 31.66 & 9.94 & \\
\hline
\end{tabular}

\footnotetext{
a initial Metric Tons of Uranium
} 


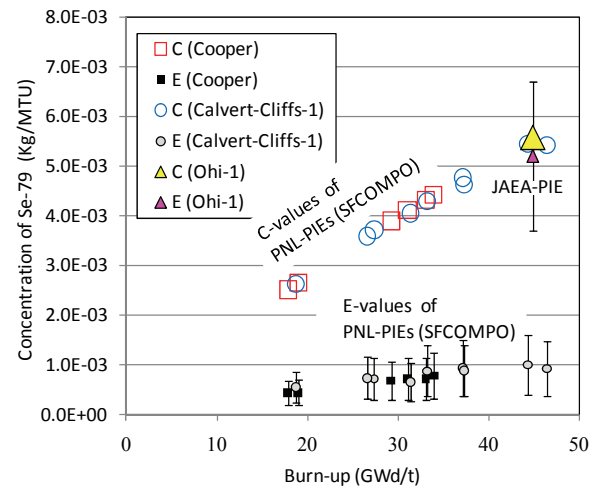

Fig. 3 Experimental and calculated values for ${ }^{79} \mathrm{Se}$ (E-values of Cooper and Calvert- Cliffs-1 are taken from SFCOMPO)

type BWR in USA), nine samples from the Calvert Cliffs-1 reactor $(14 \times 14$ type PWR in USA) and four samples from $\mathrm{H}$. B. Robinson-2 $(15 \times 15$ type PWR in USA).

Details on the sample fuel specification and irradiation conditions are summarized in the database SFCOMPO. The experimental concentrations ( $\mathrm{kg} / \mathrm{MTU})$ of fission products in each sample are also summarized in SFCOMPO for ${ }^{79} \mathrm{Se}$, ${ }^{90} \mathrm{Sr},{ }^{99} \mathrm{Tc},{ }^{126} \mathrm{Sn},{ }^{135} \mathrm{Cs}$ and ${ }^{137} \mathrm{Cs}$. In the PIE of H. B. Robinson-2, measured fission products are only ${ }^{99} \mathrm{Tc}$ and ${ }^{137} \mathrm{Cs}$.

\section{Results and Discussions}

1. ${ }^{79} \mathrm{Se}$

Figure 3 shows the experimental and calculated values of ${ }^{79} \mathrm{Se}$. The experimental values of Cooper and Calvert-Cliffs-1 PIEs are taken from SFCOMPO. The experimental error of Ohi-1 is determined as twice the standard deviation $(2 \sigma)$ of 5 repeated measurements for the same sample solution. Meanwhile, the error bars of Cooper and Calvert-Cliffs- 1 are set to be $2 \sigma$ based on experience in the PNL. 6)

The experimental value and the calculated one show a very good agreement for the PIE of Ohi-1 (JAEA-PIE) at $44.9 \mathrm{GWd} / \mathrm{t}$. The calculated values for PIEs in PNL (PNL-PIEs) have the same burn-up dependency, and the dependency is consistent with the results of JAEA-PIE. On the other hand, the experimental values in PNL-PIEs do not correspond with the above burn-up dependency. Consequently there are large discrepancies between the experimental values and calculated ones for PNL-PIEs; the averaged $\mathrm{C} / \mathrm{E}$ value is 5.5.

From the original reports ${ }^{6)}$ on PNL-PIEs, it was found that the large discrepancies are due to inaccurate half-life of ${ }^{79} \mathrm{Se}$. As shown in Fig. 4, half-life of ${ }^{79} \mathrm{Se}$ has been unclear during the last two decades.

In the PNL-PIEs, concentration of ${ }^{79} \mathrm{Se}$ was measured by liquid scintillation counter after chemical separation. Therefore, the experimental value is originally reported in the unit of Bq/MTU. After that, it was converted to the reevaluated experimental value in $\mathrm{kg} / \mathrm{MTU}$, for the compilation of SFCOMPO, using a half-life value smaller than the latest one. Since all burn-up calculations are performed using atomic number densities, accurate half-lives are necessary to

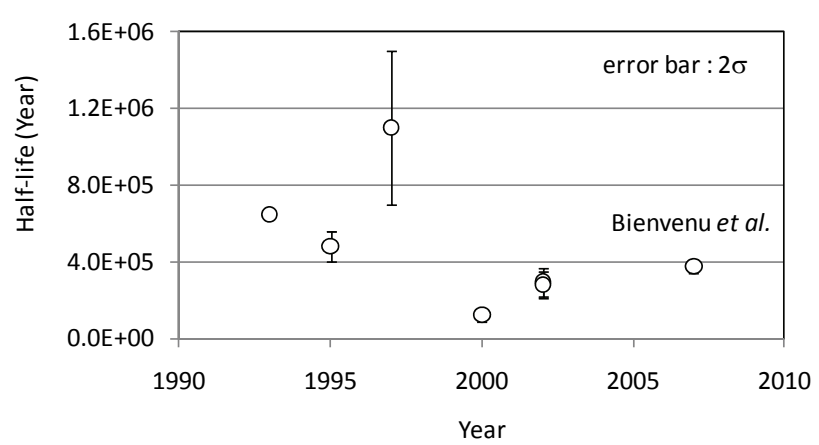

Fig. 4 Measurements of half-life of ${ }^{79} \mathrm{Se}$

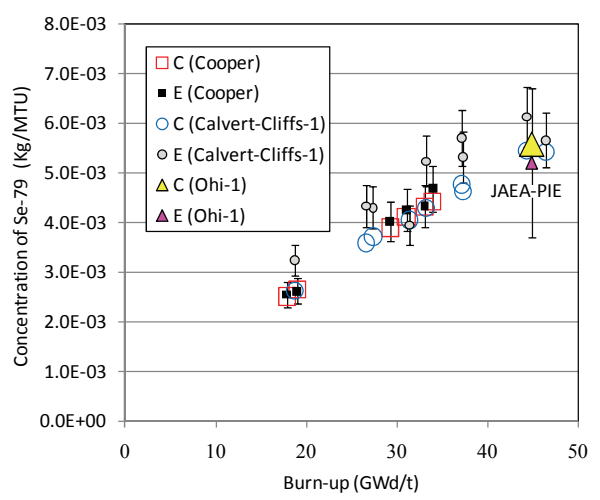

Fig. 5 Experimental and calculated values for ${ }^{79} \mathrm{Se}$ (E-values of Cooper and Calvert-Cliffs- 1 are modified with the latest half-life of ${ }^{79} \mathrm{Se}$ )

compare with the experimental values of PNL-PIEs. On the other hand, half-lives are not necessary for the experimental values of JAEA-PIE, because the concentrations of LLFPs were directly measured by ICP-QMS.

In Fig. 5, the experimental values of ${ }^{79} \mathrm{Se}$ for PNL-PIEs are modified; the measured values in PNL-PIEs are converted with the latest half-life of ${ }^{79} \mathrm{Se}$ obtained by Bienvenu et al. (2007). As a result, the averaged C/E for 15 samples in PNL-PIEs is $0.92 \pm 0.15(2 \sigma)$, which is quite consistent with the $\mathrm{C} / \mathrm{E}$ value $(1.07 \pm 0.29)$ obtained from JAEA-PIE.

\section{2. ${ }^{126} \mathrm{Sn}$}

In PNL-PIEs, ${ }^{126} \mathrm{Sn}$ (radioactively balanced ${ }^{126} \mathrm{Sb}$ ) was measured by $\mathrm{Ge}(\mathrm{Li})$ gamma spectrometry. As shown in Fig. 6, old half-life of ${ }^{126} \mathrm{Sn}$ obtained by Orth et al. had been used for a long time. It may be still used in many burn-up calculation codes. Since SFCOMPO also employed this value $\left(1 \times 10^{5}\right.$ year $)$ to convert the experimental values of PNL-PIEs, most of C/E values for ${ }^{126} \mathrm{Sn}$ exceed 3.0 as seen in Fig. 7. Here, the half-life of SFCOMPO was estimated from the original values in $\mathrm{Bq} / \mathrm{MTU}$ and E-values of SFCOMP in $\mathrm{kg} / \mathrm{MTU}$.

The modified experimental values for ${ }^{126} \mathrm{Sn}$ in PNL-PIEs are shown in Fig. 8, where the latest half-life by Bienvenu et al. (2009) is employed. Then, the averaged $\mathrm{C} / \mathrm{E}$ value for 15 samples is $1.53 \pm 0.26(2 \sigma)$, while the $\mathrm{C} / \mathrm{E}$ value from JAEA-PIE is $1.24 \pm 0.19$.

The possible reasons of these overestimations are 1) part of $\mathrm{Sn}$ initially existed in the sample $\mathrm{UO}_{2}$ fragment precipi- 


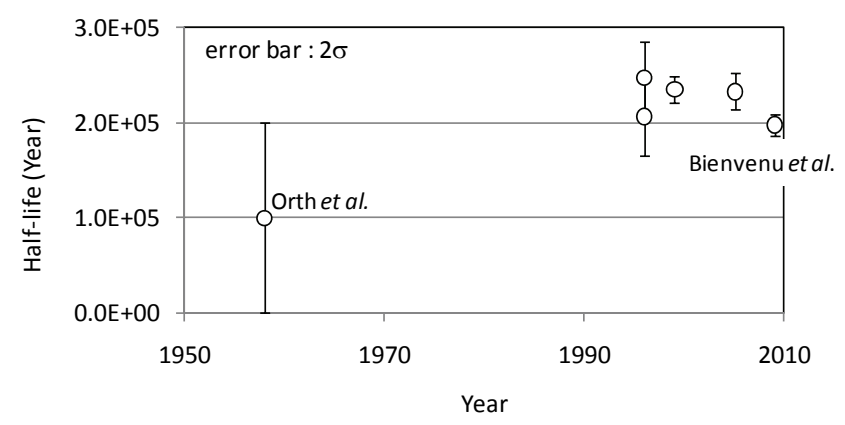

Fig. 6 Measurements of half-life of ${ }^{126} \mathrm{Sn}$

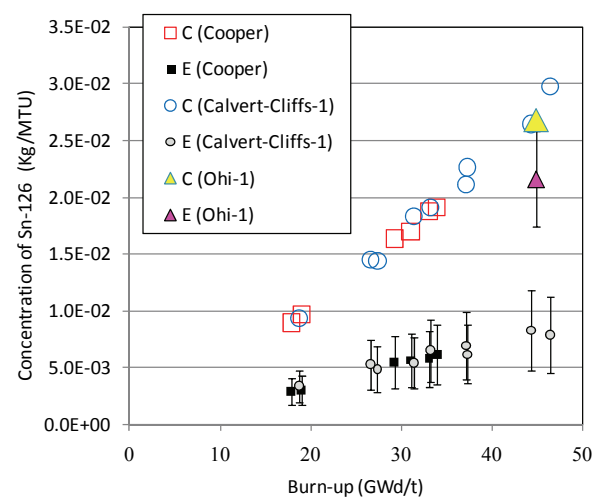

Fig. 7 Experimental and calculated values for ${ }^{126} \mathrm{Sn}$ (E-values of Cooper and Calvert Cliffs-1 are taken from SFCOMPO)

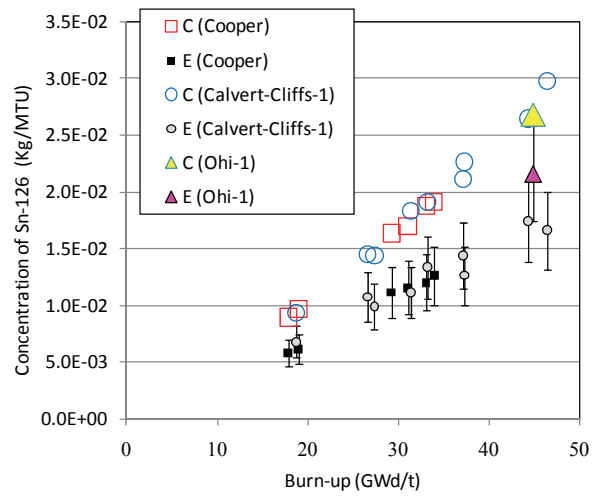

Fig. 8 Experimental and calculated values for ${ }^{126} \mathrm{Sn}$ (E-values of Cooper and Calvert Cliffs-1 are modified with the latest half-life of ${ }^{126} \mathrm{Sn}$ )

tated as an insoluble residue during the dissolution process, 2) Fission yields of ${ }^{126} \mathrm{Sn}$ is too large. The relative errors $(2 \sigma)$ of cumulative fission yields of ${ }^{126} \mathrm{Sn}$ in JENDL-4.0 are $16 \%$ for thermal fissions of ${ }^{235} \mathrm{U}$ and ${ }^{239} \mathrm{Pu}$. Any way, it is confirmed that the experimental result of JAEA-PIE for ${ }^{126} \mathrm{Sn}$ is almost consistent with those of PNL-PIEs.

\section{3. ${ }^{99} \mathrm{Tc}$}

In PNL-PIEs, ${ }^{99}$ Tc was measured by $\beta$-counting after chemical separation. However, half-life of ${ }^{99} \mathrm{Tc}$ has not been drastically changed like ${ }^{79} \mathrm{Se}$ and ${ }^{126} \mathrm{Sn}$. The difference of half-lives between the value used in SFCOMPO and the latest one employed in MVP-BURN is less than 3\%.

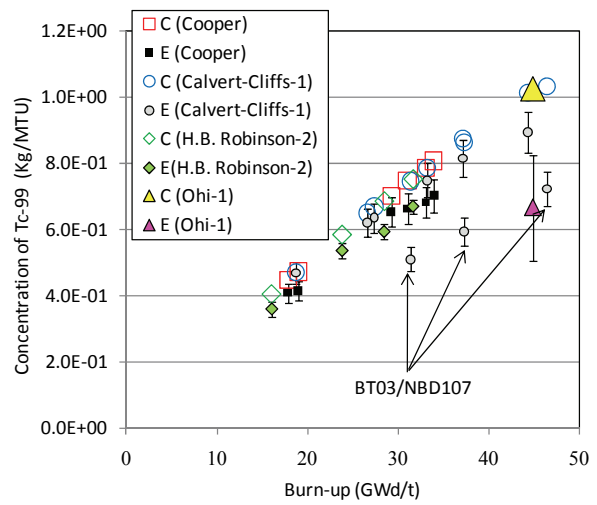

Fig. 9 Experimental and calculated values for ${ }^{99} \mathrm{Tc}$ (E-values of Cooper, Calvert Cliffs-1 and H. B. Robinson-2 are modified with the latest half-life of ${ }^{99} \mathrm{Tc}$ )

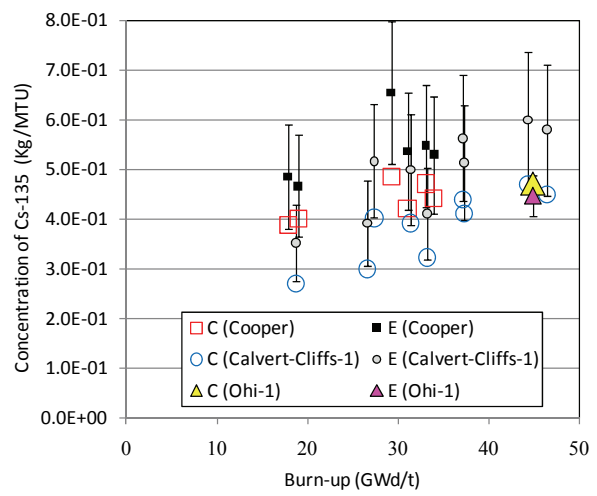

Fig. 10 Experimental and calculated values for ${ }^{135} \mathrm{Cs}$ (E-values of Cooper and Calvert Cliffs-1 are taken from SFCOMPO)

The modified experimental values for ${ }^{99} \mathrm{Tc}$ are shown in Fig. 9 together with the calculated ones. The $\mathrm{C} / \mathrm{E}$ values for PNL-PIEs including H. B. Robinson-2 are about 1.1 except for 3 samples cut out from the same fuel rods (BT03), whose $\mathrm{C} / \mathrm{E}$ values are around 1.5 . The $\mathrm{C} / \mathrm{E}$ value for Ohi- 1 is also 1.5 , which is beyond the experimental error $(2 \sigma)$. This spread of the $\mathrm{C} / \mathrm{E}$ values could not be explained by a case study where various burn-up conditions (e.g. water density, power history, etc.) were changed in the range of possibilities. In addition, the relative errors of cumulative fission yields of ${ }^{99} \mathrm{Tc}$ are less than $3 \%(2 \sigma)$ for ${ }^{235} \mathrm{U}$ and ${ }^{239} \mathrm{Pu}$ in JENDL-4.0. Thus, it is supposed that the spread is mainly due to the missing of ${ }^{99} \mathrm{Tc}$ into the insoluble residue. This means that accurate prediction of ${ }^{99} \mathrm{Tc}$ is difficult until the amount of ${ }^{99} \mathrm{Tc}$ in the insoluble residue is determined. However, as seen in Fig. 9, upper limit of E-values depending on burn-up can be well estimated by the present calculation.

\section{4. ${ }^{135} \mathrm{Cs}$}

Figure 10 shows the experimental and calculated values of ${ }^{135} \mathrm{Cs}$. The experimental values of PNL-PIEs are taken from SFCOMPO. In contrast, in Fig. 11, the experimental values of PNL-PIEs are modified with the half-life $\left(2.30 \times 10^{6}\right.$ year $)$ employed in MVP-BURN.

In Fig. 11, the averaged $\mathrm{C} / \mathrm{E}$ value for the 15 samples of 


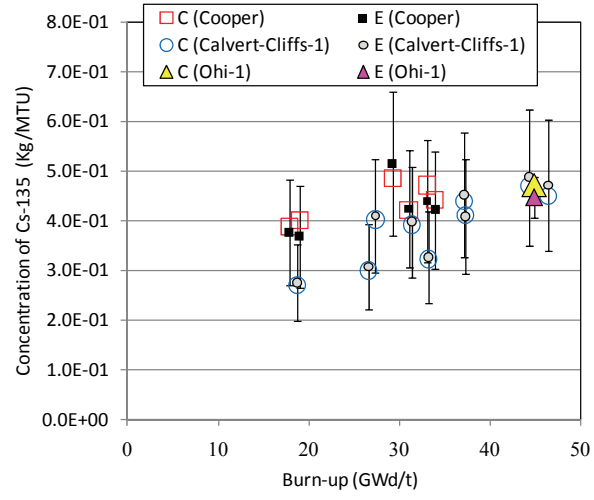

Fig. 11 Experimental and calculated values for ${ }^{135} \mathrm{Cs}$ (E-values of Cooper and Calvert Cliffs- 1 are modified with the latest half-life of ${ }^{135} \mathrm{Cs}$ )

PNL-PIEs is $1.00 \pm 0.09(2 \sigma)$, and the $\mathrm{C} / \mathrm{E}$ value for JAEA-PIE is $1.06 \pm 0.09$. Thus, it was confirmed that the prediction accuracy of MVP-BURN and the latest nuclear data is quite good for ${ }^{135} \mathrm{Cs}$, and the measurement data by JAEA is well consistent with those obtained from PIEs by PNL.

\section{Other Fission Products}

The averaged $\mathrm{C} / \mathrm{E}$ values for ${ }^{90} \mathrm{Sr}$ and ${ }^{137} \mathrm{Cs}$ are summarized in Table 2. For both nuclides, MVP-BURN can predict their concentrations within $10 \%$. Although these nuclides are not LLFPs, the $\mathrm{C} / \mathrm{E}$ vales close to unity indicate the reliability of the assay data employed in this study.

\section{Conclusion}

For the accurate inventory estimation of long-lived fission products (LLFPs) in LWR spent nuclear fuels, such as ${ }^{79} \mathrm{Se}$, ${ }^{99} \mathrm{Tc},{ }^{126} \mathrm{Sn}$ and ${ }^{135} \mathrm{Cs}$, a new burn-up chain model was developed for MVP-BURN. In addition, the latest nuclear data were employed for neutron-induced cross sections (JENDL-4.0), fission yields (JENDL-4.0), isomeric ratios (JENDL-4.0), half-lives (ENSDF Oct. 2008 and data by Bienvenu et al. for ${ }^{79} \mathrm{Se}$ and $\left.{ }^{126} \mathrm{Sn}\right)$.

The chain model and the latest nuclear data were applied to four post irradiation examinations including measurements of above four LLFPs; a new PIE (Ohi-1) by JAEA and three PIEs (Cooper, Calvert Cliffs- 1 and H. B. Robinson-2) by PNL.

From these PIE analyses, it has been confirmed that the assay data by JAEA is consistent with the assay data for 15 (19 for ${ }^{99} \mathrm{Tc}$ ) samples obtained by PNL with the different technique from JAEA's. It also has been confirmed that the present data and method can predict inventories (kg/MTU) of ${ }^{79} \mathrm{Se}$ and ${ }^{135} \mathrm{Cs}$ in $\mathrm{UO}_{2}$ spent nuclear fuels within about $10 \%$. In contrast, overestimations were observed for ${ }^{99} \mathrm{Tc}$ and ${ }^{126} \mathrm{Sn}$, by up to about $50 \%$. Possible reasons of the overestimations are the effect of insoluble residue produced during sample dissolution and / or errors of fission yields in the analyses. In either reason, upper limit of ${ }^{99} \mathrm{Tc}$ and ${ }^{126} \mathrm{Sn}$ can be estimated by the present data and method for burn-up calculations.
Table 2 Averaged C/E values of ${ }^{90} \mathrm{Sr}$ and ${ }^{137} \mathrm{Cs}$

\begin{tabular}{|c|c|c|c|c|}
\hline & \multicolumn{2}{|c|}{ Sr-90 } & \multicolumn{2}{c|}{ Cs-137 } \\
\hline PIE reactor & $<\mathrm{C} / \mathrm{E}>$ & $2 \sigma$ & $<\mathrm{C} / \mathrm{E}>$ & $2 \sigma$ \\
\hline Cooper & 1.04 & 0.05 & 1.00 & 0.08 \\
\hline Calvert Cliffs-1 & 1.02 & 0.03 & 0.98 & 0.03 \\
\hline H. B. Robinson-2 & NA & NA & 0.98 & 0.04 \\
\hline Ohi-1 & NA & NA & 0.99 & 0.09 \\
\hline
\end{tabular}

NA: not measured

\section{Acknowledgements}

Post irradiation examination of the Ohi-1 sample fuel in this work was supported by a fund from Tokyo Electric Power Company, Hokkaido Electric Power Company, Tohoku Electric Power Company, Chubu Electric Power Company, Hokuriku Electric Power Company, Kansai Electric Power Company, Chugoku Electric Power Company, Shikoku Electric Power Company, Kyusyu Electric Power Company, Japan Atomic Power Company, and Electric Power Development Co., Ltd.

\section{References}

1) M. Ishikawa, S. Kaneko, K. Kitayama, K. Ishiguro, H. Ueda, K. Wakasugi, N. Shinohara, K. Okumura, M. Chino, N. Moriya, "Study on Improvement in Reliability of Inventory Assessment in Vitrified Waste for Long-Term Safety of Geological Disposal," Trans. At. Energy Soc. Japan, 8[4], 304 (2009), [in Japanese].

2) S. Asai, Y. Hanzawa, K. Okumura, N. Shinohara, J. Inagawa, S. Hotoku, K. Suzuki, S. Kaneko, "Determination of ${ }^{79} \mathrm{Se}$ and ${ }^{135} \mathrm{Cs}$ in Spent Nuclear Fuel for Inventory Estimation of High-Level Radioactive Wastes," J. Nucl. Sci. Technol., 48[5], 851 (2011).

3) S. Asai, Y. Hanzawa, K. Okumura, H. Suzuki, M. Toshimitsu, N. Shinohara, S. Kaneko, K. Suzuki, "Comparison of Post-Irradiation Experimental Data and Theoretical Calculations for Inventory Estimation of Long-lived Fission Products in Spent Nuclear Fuel," Proc. $13^{\text {th }}$ Int. Conf. on Environmental Remediation and Radioactive Waste Management ICEM2010, Tsukuba, Japan, Oct. 3-7, 2010, paper-ID 40101 (2010).

4) K. Okumura, T. Mori, N. Nakagawa, K. Kaneko, "Validation of a continuous-energy Monte Carlo burn-up code MVP-BURN and its application to analysis of post irradiation experiment," $J$. Nucl. Sci. Technol., 37[2], 128-138 (2000).

5) K. Shibata, O. Iwamoto, T. Nakagawa et al., "JENDL-4.0: A New Library for Nuclear Science and Engineering," J. Nucl. Sci. Technol., 48[1], 1-30 (2011).

6) R. J. Guenther, D. E. Blahnik, T. K. Campbell et al., Characterization of Spent Fuel Approved Testing Material -ATM-103/-104/-105/-106, Pacific Northwest Laboratory, PNL-5109-103 (1988), -104 (1991), -105 (1991), -106 (1988).

7) J. O. Barner, Characterization of LWR Spent Fuel MCC-Approved Testing Material-ATM-101, PNL-5109 Rev.1, Pacific Northwest Laboratory (1988).

8) H. Mochizuki, K. Suyama, Y. Nomura, H. Okuno, Spent Fuel Composition Database System on WWW - SFCOMPO on WWW Ver.2 -, JAERI-Data/Code 2001-020, Japan Atomic Energy Research Institute (JAERI) (2001), [in Japanese].

For the latest information of SFCOMPO, See the URL of 
OECD/NEA, http://www.nea.fr/sfcompo/

9) Y. Nagaya, K. Okumura, T. Mori, M. Nakagawa, $M V P / G M V P$ II: General Purpose Monte Carlo Codes for Neutron and Photon Transport Calculations based on Continuous Energy and Multigroup Methods, JAERI 1348 (2005).

10) K. Tasaka, DCHAIN Code for Analysis of Build up and Decay of Nuclides, JAERI 1250, Japan Atomic Energy Research Institute (JAERI) (1977).

11) National Nuclear Data Center, "Evaluated Nuclear Structure Data File (ENSDF), http://www.nndc.bnl.gov/.

12) P. Bienvenu, P. Cassette, G. Andreoletti et al., "A new determi- nation of ${ }^{79}$ Se half-life," Appl. Radiat. Isot., 65, 355 (2007).

13) P. Bienvenu, L. Ferreux, G. Andreoletti et al., "Determination of ${ }^{126} \mathrm{Sn}$ half-life from ICP-MS and gamma spectrometry measurements," Radiochim. Acta, 97, 687 (2009).

14) Y. Nakahara, K. Suyama, T. Suzaki (Eds.), Technical Development on Burn-up Credit for Spent LWR Fuels, JAERI-Tech 2000-071, Japan Atomic Energy Research Institute (JAERI) (2000).

15) G. Chiba, K. Okumura, K. Sugino et al. "JENDL-4.0 Benchmarking for Fission Reactor Applications," J. Nucl. Sci. Technol., 48[2], 172-187 (2011). 